\title{
Oil accumulation in the model green alga Chlamydomonas reinhardtii: characterization, variability between common laboratory strains and relationship with starch reserves
}

Magali Siaut ${ }^{1,2,3,4}$, Stéphan Cuiné ${ }^{1,2,3}$, Caroline Cagnon ${ }^{1,2,3}$, Boris Fessler ${ }^{1,2,3}$, Mai Nguyen 1,2,3 , Patrick Carrier $^{1,2,3}$, Audrey Beyly ${ }^{1,2,3}$, Fred Beisson ${ }^{1,2,3}$, Christian Triantaphylidès ${ }^{1,2,3}$, Yonghua Li-Beisson ${ }^{1,2,3^{*}}$, Gilles Peltier ${ }^{1,2,3}$

\begin{abstract}
Background: When cultivated under stress conditions, many microalgae species accumulate both starch and oil (triacylglycerols). The model green microalga Chlamydomonas reinhardtii has recently emerged as a model to test genetic engineering or cultivation strategies aiming at increasing lipid yields for biodiesel production. Blocking starch synthesis has been suggested as a way to boost oil accumulation. Here, we characterize the triacylglycerol (TAG) accumulation process in Chlamydomonas and quantify TAGs in various wild-type and starchless strains.

Results: In response to nitrogen deficiency, Chlamydomonas reinhardtii produced TAGs enriched in palmitic, oleic and linoleic acids that accumulated in oil-bodies. Oil synthesis was maximal between 2 and 3 days following nitrogen depletion and reached a plateau around day 5 . In the first 48 hours of oil deposition, a $\sim 80 \%$ reduction in the major plastidial membrane lipids occurred. Upon nitrogen re-supply, mobilization of TAGs started after starch degradation but was completed within 24 hours. Comparison of oil content in five common laboratory strains (CC124, CC125, CW15, CC1690 and 11-32A) revealed a high variability, from $2 \mu \mathrm{g}$ TAG per million cell in CC124 to $11 \mathrm{\mu g}$ in 11-32A. Quantification of TAGs on a cell basis in three mutants affected in starch synthesis (cw15sta1-2, cW15sta6 and (W15sta7-1) showed that blocking starch synthesis did not result in TAG over-accumulation compared to their direct progenitor, the arginine auxotroph strain 330. Moreover, no significant correlation was found between cellular oil and starch levels among the twenty wild-type, mutants and complemented strains tested. By contrast, cellular oil content was found to increase steeply with salt concentration in the growth medium. At $100 \mathrm{mM} \mathrm{NaCl}$, oil level similar to nitrogen depletion conditions could be reached in CC124 strain.

Conclusion: A reference basis for future genetic studies of oil metabolism in Chlamydomonas is provided. Results highlight the importance of using direct progenitors as control strains when assessing the effect of mutations on oil content. They also suggest the existence in Chlamydomonas of complex interplays between oil synthesis, genetic background and stress conditions. Optimization of such interactions is an alternative to targeted metabolic engineering strategies in the search for high oil yields.
\end{abstract}

\footnotetext{
* Correspondence: yonghua.li@cea.fr

${ }^{1}$ Commissariat à l'Energie Atomique et aux Energies Alternatives (CEA), Direction of Life Sciences, Institute for Environmental Biology and Biotechnology, Laboratory of Bioenergetics and Biotechnology of Bacteria and Microalgae, CEA Cadarache, 13108 Saint-Paul-lez-Durance, France Full list of author information is available at the end of the article
} 


\section{Background}

Bioethanol and biodiesel are currently produced from food crops such as sugar beet, sugar cane, soybean or rapeseed, thus competing with land use for food production and urging to find new feedstocks [1]. Due to their high surface productivity, microalgae are considered as a promising way of producing biofuels [2-4]. Under standard growth conditions, microalgal biomass is mainly composed of proteins, cell wall carbohydrates and membrane lipids. Accumulation of energy-rich reserve compounds such as starch and storage lipids (oil) occurs in many microalgae under conditions of nutrient shortage such as nitrogen $(\mathrm{N})$ deficiency $[3,5]$.

Oil is largely composed of long-chain triacylglycerols (TAG) and represents a form of energy storage 2.25 times greater than starch on a weight basis [6]. TAGs can be converted to biodiesel by chemical transesterification of its fatty acids and is thus a highly desirable storage compound. Some microalgae species accumulate up to $50 \%$ TAG on a dry weight basis in response to $\mathrm{N}$ deficiency [2,7]. Despite high biomass productivity and ability to accumulate high oil amounts, microalgal biodiesel is currently not competitive for several reasons. Firstly, contamination of microalgal cutltures by bacteria, viruses and other microalgae is a common issue. Secondly, the cost of microalgae cultivation, biomass harvest and oil extraction contribute significantly to the overall costs. Thirdly, intracellular oil accumulation requires a phase of nutrient starvation, which severely decreases the overall productivity of the system $[2,3]$. It is therefore clear that competitiveness of microalgal biodiesel will depend on improvements in both cultivation and harvesting technologies [4] as well as in strain performances [3].

Improving microalgal strain performances requires a better understanding in model microalgae of the mechanisms and regulations of carbon fixation, carbon allocation between biosynthetic pathways and induction by stresses. The green unicellular alga Chlamydomonas reinhardtii is a widely recognized model organism to investigate numerous biological functions, including photosynthesis [8], starch metabolism [5,9] or flagella [10]. The recent sequencing of its whole genome [11], the availability of numerous molecular tools including transformation of the three (nuclear, plastid and mitochondrial) genomes, and the existence of a sexual cycle allowing genetic studies make C. reinhardtii an attractive model for molecular investigations [12]. In addition to its well known starch reserves, $C$. reinhardtii has also been observed to accumulate intracellular oil droplets under N limiting conditions $[13,14]$. Pathways of TAG biosynthesis are still poorly documented in microalgae including in C. reinhardtii and most putative reactions are based on similarity of microalgal sequences to characterized proteins from bacteria, yeasts and higher plants [15]. Starch biosynthesis on the other hand has been particularly well-studied in this organism due to the isolation of several starchless mutants [13].

Whether starch synthesis competes with oil synthesis for carbon precursors is an important question. If such a competition exists, shutting down starch biosynthesis could be a simple way to increase the amount of oil stored in microalgal cells. Increased amount of oil on a dry weight basis has been reported for starchless mutants in Chorella pyrenoidosa [16] and more recently in Chlamydomonas reinhardtii [17] but no direct quantitative estimates of the oil content per cell were provided. Another study reports a 1.5 to 2.0 fold increase in oil per cell in a Chlamydomonas starchless mutant [18], which suggests a competition between oil and starch syntheses. However, recent data showing that complemented strains of $C$. reinhardtii starchless mutants have both high oil and high starch content [19] seems inconsistent with a competition hypothesis. The first studies of oil mutants in Chlamydomonas thus highlight the gaps existing in our understanding of oil deposition in this species and on the factors that might be critical when assessing the effect of mutations on oil content. Gaining insights into these issues is important because Chlamydomonas will increasingly be used as a model to study oil synthesis and isolate oil mutants.

Here, we characterize the oil accumulation process in C. reinhardtii by investigating the kinetics of oil deposition and mobilization comparatively to starch, as well as the changes occurring in major plastidial membrane lipids during TAG accumulation. We also show that common laboratory strains of Chlamydomonas widely used as references in mutant comparisons have up to 5 -fold variation in their capacity to accumulate oil. Comparison of starchless mutants using appropriate reference strain on a per cell basis shows that blocking starch synthesis has no significant effect on oil accumulation in the $c w 15$ background. Finally, it is shown that in C. reinhardtii CC124 (137C) wild-type strain, oil accumulation can be induced by salt stress, which could advantageously replace nitrogen depletion in mutant screens.

\section{Results \\ Cellular oil content varies up to 5 -fold in common laboratory strains of $C$. reinhardtii}

Like many microalgae, $C$. reinhardtii accumulates starch when cultivated in N-depleted medium [9]. Recently, it has become clear that under these stress conditions $C$. reinhardtii also synthesize neutral lipids $[14,18]$. Accumulation of these compounds can be monitored by a 
simple stain with Nile red, a fluorescent dye emitting a yellow fluorescence signal (around $580 \mathrm{~nm}$ ) in the presence of neutral lipids [20]. Using this simple technique, accumulation of neutral lipids was followed during a 4-day $\mathrm{N}$ starvation in $c w 15$, a common laboratory strain of $C$. reinhardtii. Clear qualitative differences in the level of neutral lipids accumulated within cells could be seen before and after nitrogen removal (Figure 1).

To determine if the neutral lipids detected were indeed triacylglycerols (TAGs), total cellular lipids were extracted and separated by high performance thin layer chromatography (HPTLC). The TAG fraction was identified by co-migration with a purified TAG standard, recovered from the HPTLC plate and its fatty acid content analyzed by gas chromatography with flame ionization detection (GC-FID) (Figure 2A). C. reinhardtii TAGs induced by $\mathrm{N}$ depletion had a fatty acid composition dominated by 16:0 (palmitic acid), 9c-18:1 (oleic acid) and 9c,12c-18:2 (linoleic acid), which is similar to many plant oils. This was in clear contrast with the fatty acid profile of $C$. reinhardtii whole cells grown under standard conditions (TAP medium), whose major lipid species were membrane lipids and were thus rich in polyunsaturated species such as $9 \mathrm{c}, 12 \mathrm{c}, 15 \mathrm{c}-18: 3$ ( $\alpha$-linolenic acid), 4c,7c,10c,13c-16:4, 5c,9c,12c-18:3, and 5c,9c,12c,15c-18:4 (Figure 2B)

Amount of TAGs measured by HPTLC/densitometry and HPTLC/GC-FID were not significantly different (data not shown). Densitometry was therefore used routinely to quantify TAGs. Oil content was measured for $c w 15, \mathrm{CC} 124$ as well as three other strains grown at the same time in flasks agitated in an incubator where light intensity and temperature were controlled. While under standard growth conditions (TAP medium) all strains were found to store low TAG amounts $\left(<1 \mu \mathrm{g} 10^{-6}\right.$ cells), all strains accumulated TAGs in response to a 2-day nitrogen depletion, but interestingly not to the same levels (Figure 3A). TAG amounts varied over 5fold, ranging from about 2 to $11 \mu \mathrm{g}$ per million cell in CC124 and11-32A respectively, with intermediate levels of TAGs found in other strains. These five laboratory strains also showed a variability in their capacity to accumulate starch following nitrogen deprivation, but the variation in starch content was clearly lower than for oil (2-fold, from 30 to about $60 \mu \mathrm{g}$ per million cell) (Figure 3B).

The bulk of plastidial membrane lipids is degraded at the beginning of the oil accumulation phase

To characterize better the reserve deposition process triggered by nitrogen deprivation, a strain with high TAG content was chosen ( $c w 15)$ for further studies. Amounts of starch, oil and chlorophyll per cell were followed for 7 days after $\mathrm{N}$ removal. While starch accumulation was observed after 1 day following nitrogen depletion (TAP-N media) and had already reached high levels by day 2 (about $60 \mu \mathrm{g}$ per million cell), TAGs started to accumulate at a much slower rate, reaching maximal level after 5 days only $(40 \mu \mathrm{g}$ per million cell) (Figure 4). Phenotypically, nitrogen-starved cells had a yellowish appearance compared to those grown under nutrient replete conditions. Quantification of chlorophyll content showed a sharp decrease from $3 \mu \mathrm{g} 10^{-6}$ cells to $0.5 \mu \mathrm{g} 10^{-6}$ cells as $\mathrm{N}$ deficiency progressed (Figure 4). A similar pattern of lipid accumulation was also observed in the low-oil accumulator CC124 (see additional file 1). Changes in cellular structures caused by nitrogen depletion were observed by transmission electron microscopy. In $C$. reinhardtii, a single cup-shaped plastid takes up over two thirds of the total cellular volume when cultivated under nutrient replete conditions [21], where neither starch granule nor lipid bodies could be detected. The accumulation of starch granules and oilbodies as well as a reduction in plastidial membranes
$\mathrm{TAP}+\mathbf{N}$

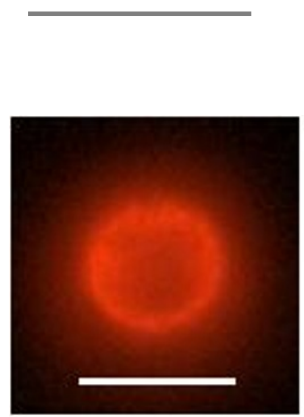

\section{Days of starvation (TAP-N)}

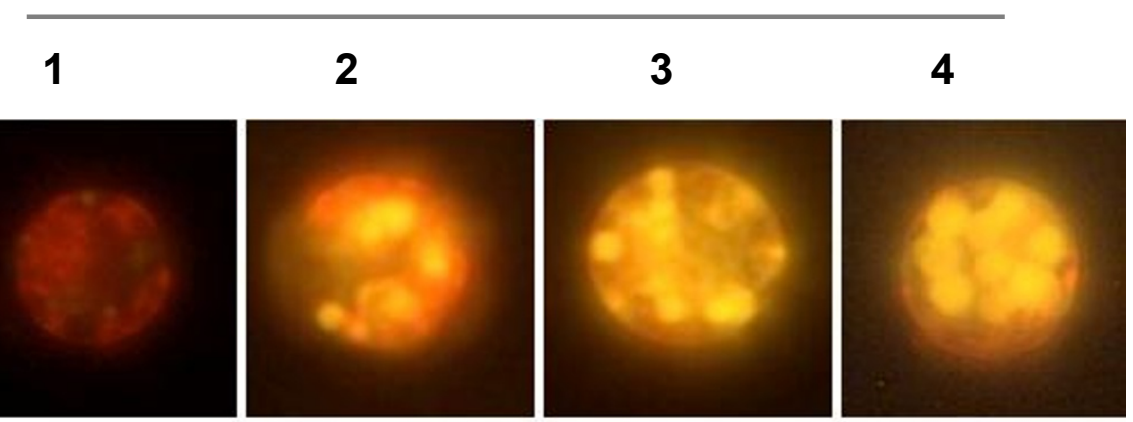

Figure 1 Detection of neutral lipid accumulation in $c w 15$, a common laboratory strain of $C$. reinhardtii using Nile red staining. The yellow fluorescence observed in the presence of Nile red indicates the presence of neutral lipids while the red fluorescence corresponds to chlorophyll autofluorescence. TAP: standard growth medium. TAP-N: nitrogen-depleted TAP medium. Bars $=8 \mu$ m. 


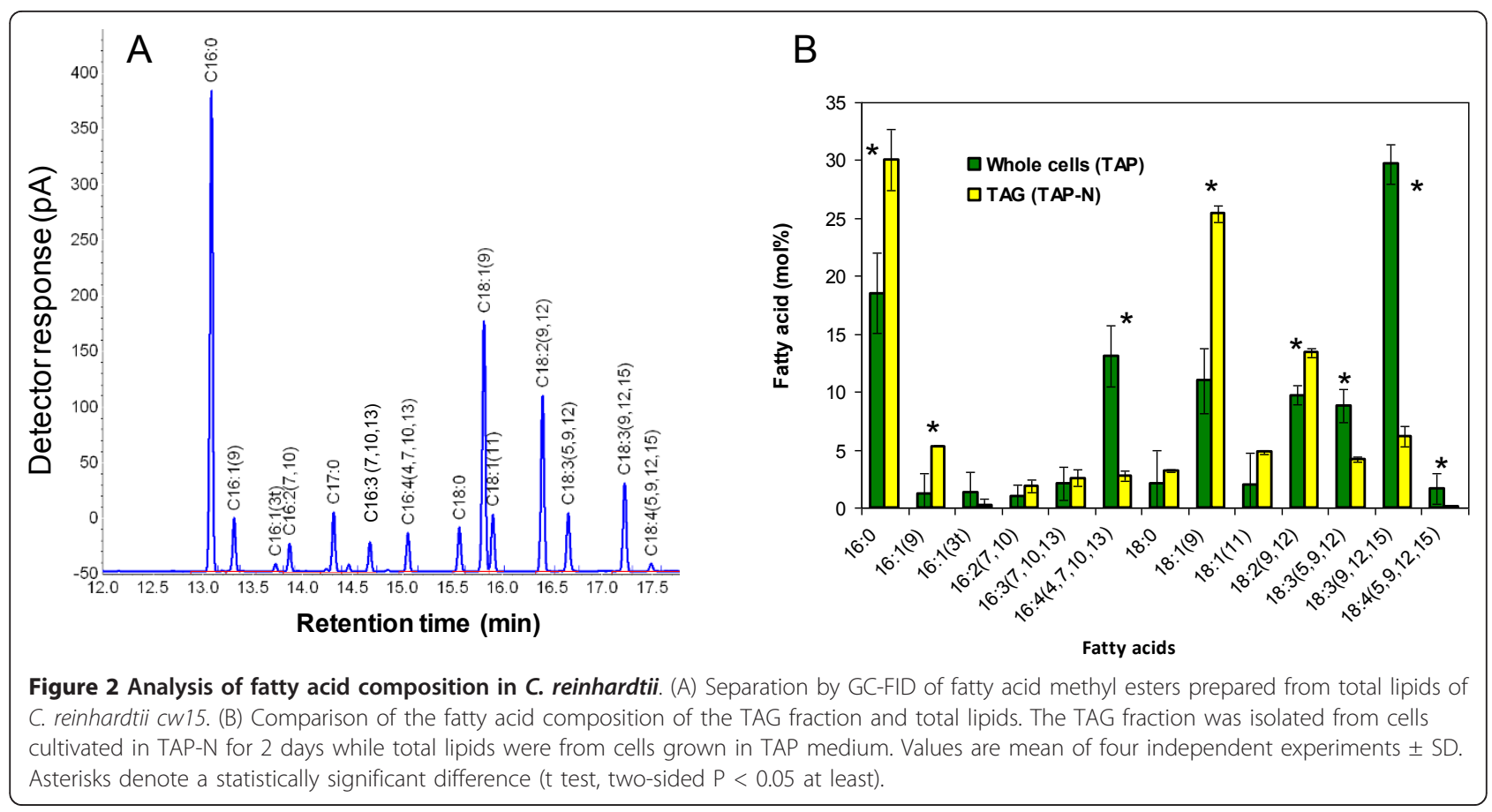

were evident in $\mathrm{N}$-starved wild-type cells (Figure 5). Taken together, these observations suggest that $\mathrm{N}$ depletion causes a reduction in the photosynthetic apparatus and a breakdown of plastidial membranes.

Separation and quantification of the major membrane lipids showed that the bulk of plastidial lipids were indeed reduced drastically (Figure 6). At day 2, while TAG amount had increased over 15-fold, there was a $>80 \%$ reduction for monogalactosyl diacylglycerol (MGDG), digalactosyl diacylglycerol (DGDG) and sulfolipid sulfoquinovosyl-diacylglycerol (SQDG). Consistently, a major change in the fatty acid profile of total

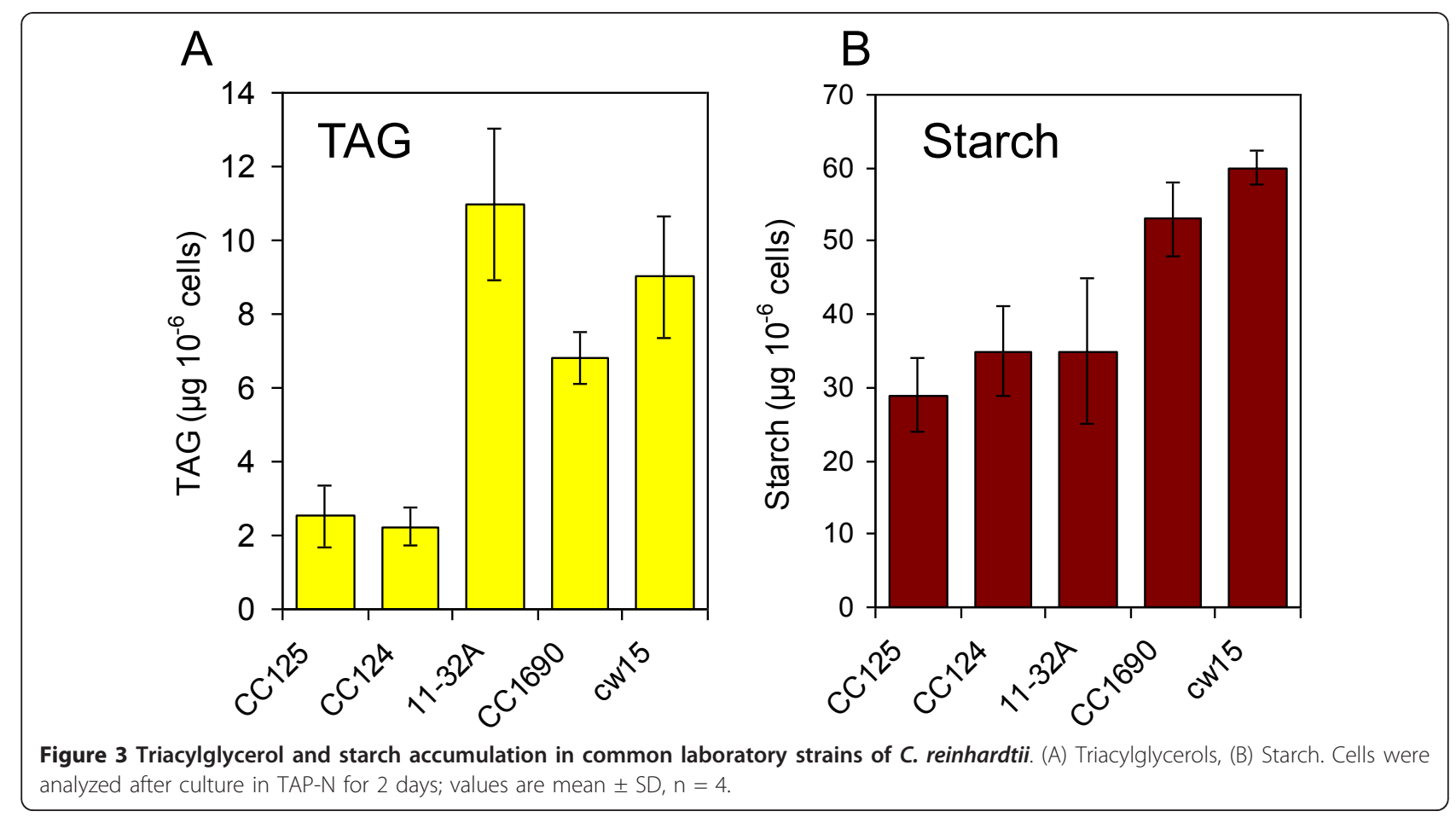




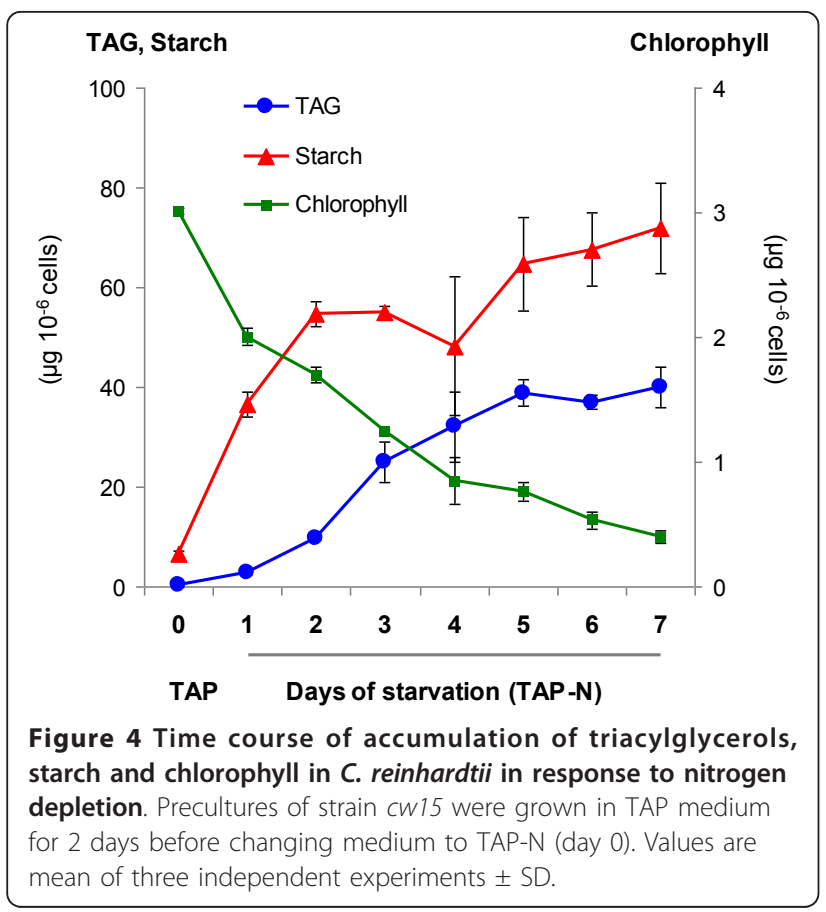

lipids (a decrease in polyunsaturated species and an increase in saturated and monounsaturated ones) was observed within the first 24 hours following $\mathrm{N}$ depletion in the culture medium (additional file 2). These results indicate that membrane breakdown does not take place at a constant rate during the 5 days of the TAG accumulation process but occurs massively at the beginning.

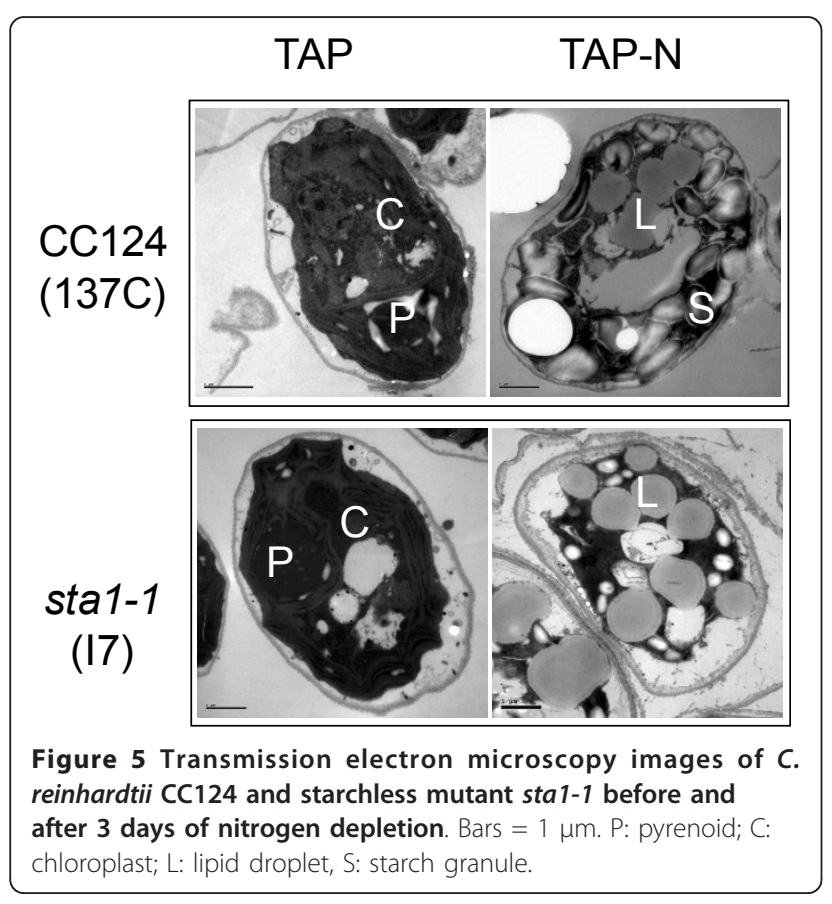

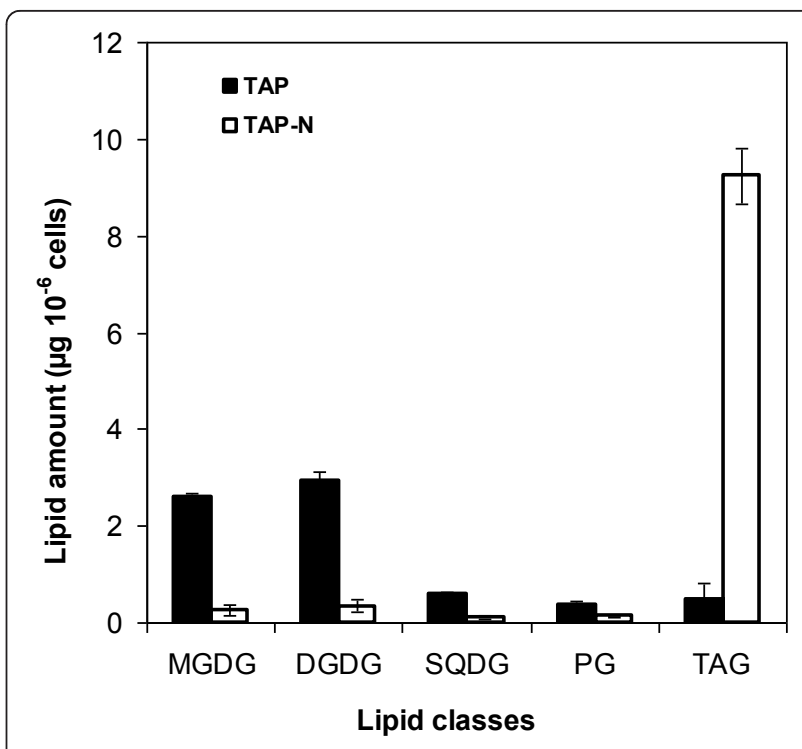

Figure 6 Changes in triacylglycerols and major plastidial lipid classes in nitrogen-starved cells. Cells were cultivated in TAP-N for 2 days. Values are mean of four independent experiments \pm SD.

No over-accumulation of TAGs occurs in cw15-derived starchless mutants compared to their progenitor

Under $\mathrm{N}$ depletion conditions, starch represents up to $40 \%$ and $80 \%$ dry weight in the C. reinhardtii strains CC124 (137C) and cw15 respectively. Based on oil content per dry weight, it has been suggested that shutting down starch synthesis results in higher oil accumulation capacity $[17,22]$. Given the high variability in TAG level observed in various common laboratory strains (Figure 3 ) several starch mutants were checked and direct progenitors were used as reference strains for assessing the effect of shutting down starch biosynthesis on oil content. Mutant strains included sta1-1 (I7), sta1-2 (BafJ3), sta6 (BafJ5) and sta7-1 (BafJ6) (Figure 7A). All these mutants, which were obtained from the Ball laboratory (University of Lille, France), either do not make starch at all, or make less than $5 \%$ of the wild-type level [13,23-25]. The expected absence or reduced amount of starch in the mutants was confirmed (Figure 7B). For the sake of simplicity, in this paper we refer to all these strains as 'starchless'. Except sta1-1, which is derived from wildtype strain CC124 (137C) by X-ray mutagenesis and has a cell wall, the other mutants were obtained from the wall-less arginine auxotroph 330 ( $c w 15$ arg $7-7)$ by insertional mutagenesis and do not have a cell wall. Therefore, the three insertional mutants are affected in both starch and cell wall and are named cw15sta1-2, cw15sta 6 and cw15sta7-1 in this study. Detailed genotypes and references of all strains used are outlined in Table 1.

Quantification of TAGs after 2 days of nitrogen depletion in the four starchless mutant strains showed that 


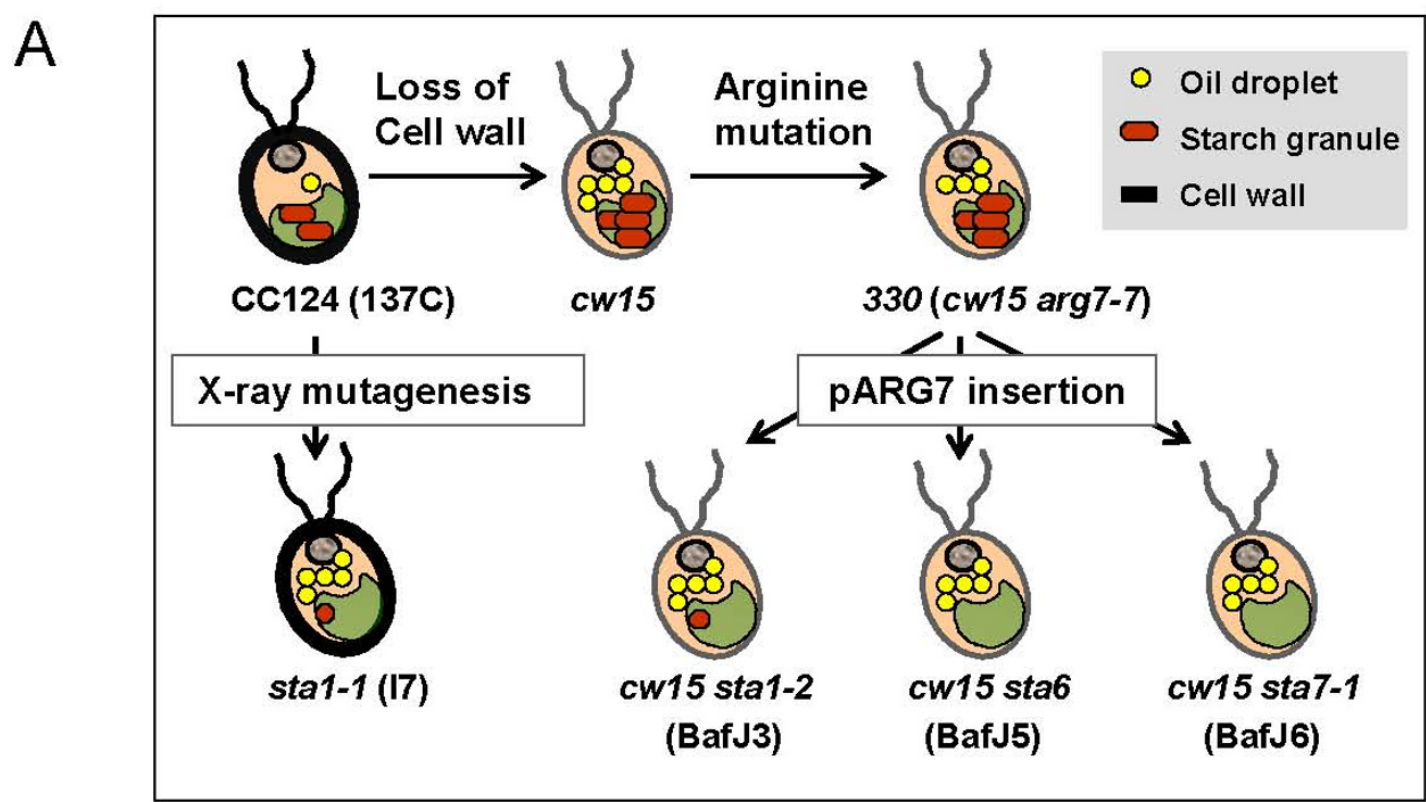

B
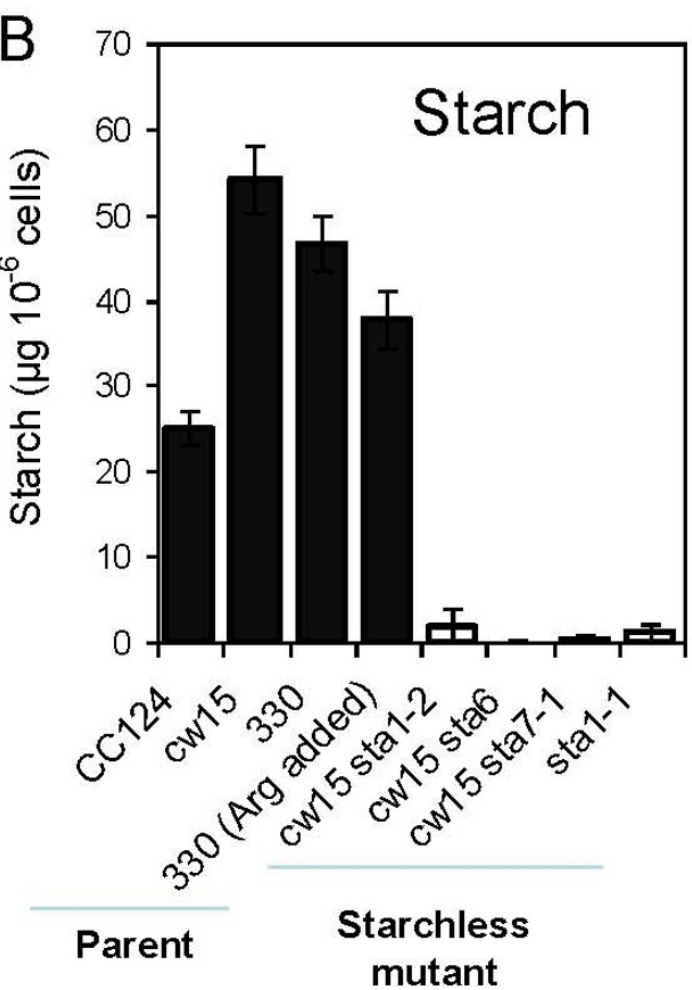

C
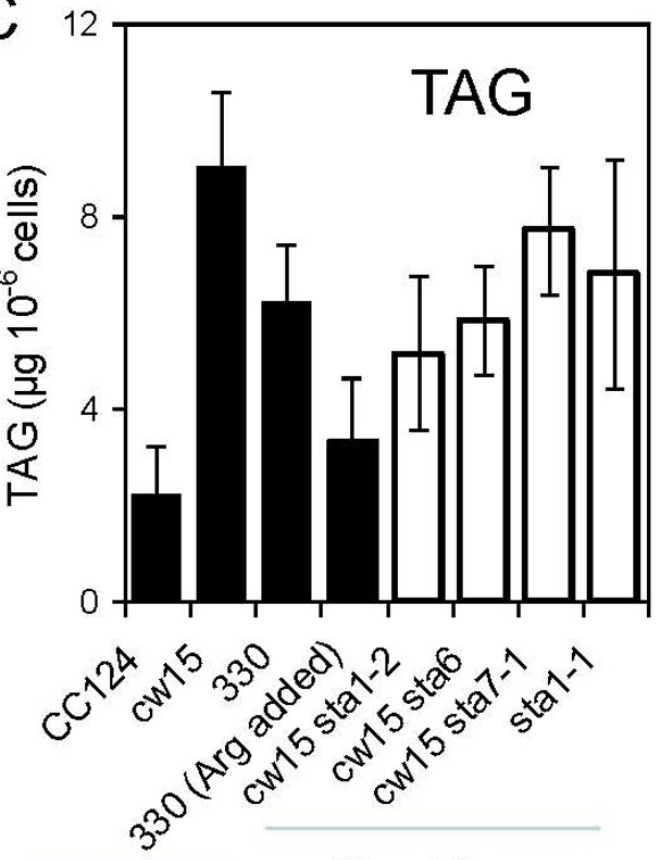

Parent

\section{Starchless} mutant

Figure $\mathbf{7}$ Comparison of oil and starch reserves in various strains of $C$. reinhardtii. (A) Relationships between the wild-type and starchless strains tested. Presence of triacylglycerol and starch reserves in N-starved cells is illustrated. Direct progenitors of the mutants are indicated. Loss of the cell wall in some strains is also highlighted. (B, C) Quantification of starch and triacylglycerol accumulation in starchless mutants (sta1-1, sta1-2, sta6, and sta7-1) and its progenitors (CC124, CW15, 330). Culture conditions: TAP-N for 2 days. Values are mean of four independent experiments \pm SD. 
Table 1 Genotypes and references of Chlamydomonas reinhardtii strains used

\begin{tabular}{|c|c|c|c|c|}
\hline Classes & Strains & Other names & Genotype & References or Source \\
\hline Wild type & CC124 & $137 \mathrm{C} \mathrm{mt-}$ & mt- nit1 nit2 & Chlamydomonas Center \\
\hline Wild type & CC125 & 137C mt+ & $m t+$ nit1 nit2 & Chlamydomonas Center \\
\hline Wild type & $11-32 \mathrm{~A}$ & & $m t+$ & CCAP collection \\
\hline Wild type & CC1690 & & $m t+$ & Chlamydomonas Center \\
\hline Wild type & cw15 mt- & CC406 & $m t-c w^{-}$ & Chlamydomonas Center \\
\hline Wild type & cw15 mt+ & CC400 & $m t+c W^{-}$ & Chlamydomonas Center \\
\hline Wild type & 330 & & $m t+$ nit1 nit2 cw15 arg7-7 & Lab of Steven Ball \\
\hline Starchless Mutants & stal-2 & BafJ3 & mt+ nit1 nit2 cw15 arg7-7 sta1-2::ARG7 & {$[24]$} \\
\hline Starchless Mutants & sta7-1 & BafJ6 & mt+ nit1 nit2 cw15 arg7-7 sta7-1::ARG7 & {$[23]$} \\
\hline Starchless Mutants & sta1-1 & 17 & mt- nit1 nit2 sta1-1 & [13] \\
\hline Starchless Mutants & sta6 & BafJ5 & mt+ nit1 nit2 cw15 arg7-7 sta6-1::ARG7 & {$[25]$} \\
\hline BafJ5 complemented lines & BafJ5C2 & & mt+ nit1 nit2 cw15 arg7-7 sta6-1::ARG7 pSL18-STA6 & Lab of Steven Ball \\
\hline BafJ5 complemented lines & BafJ5C3 & & mt+ nit1 nit2 cw15 arg7-7 sta6-1::ARG7 pSL18-STA6 & Lab of Steven Ball \\
\hline BafJ5 complemented lines & BafJ5C6 & & mt+ nit1 nit2 cw15 arg7-7 sta6-1::ARG7 pSL18-STA6 & Lab of Steven Ball \\
\hline BafJ5 complemented lines & BafJ5C7 & & mt+ nit1 nit2 cw15 arg7-7 sta6-1::ARG7 pSL18-STA6 & Lab of Steven Ball \\
\hline BafJ5 complemented lines & BafJ5C8 & & mt+ nit1 nit2 cw15 arg7-7 sta6-1::ARG7 pSL18-STA6 & Lab of Steven Ball \\
\hline BafJ5 complemented lines & BafJ5C9 & & mt+ nit1 nit2 cw15 arg7-7 sta6-1::ARG7 pSL18-STA6 & Lab of Steven Ball \\
\hline BafJ5 complemented lines & BafJ5C16 & & mt+ nit1 nit2 cw15 arg7-7 sta6-1::ARG7 pSL18-STA6 & Lab of Steven Ball \\
\hline BafJ5 complemented lines & BafJ5C18 & & mt+ nit1 nit2 cw15 arg7-7 sta6-1::ARG7 pSL18-STA6 & Lab of Steven Ball \\
\hline BafJ5 complemented lines & BafJ5C20 & & mt+ nit1 nit2 cw15 arg7-7 sta6-1::ARG7 pSL18-STA6 & Lab of Steven Ball \\
\hline
\end{tabular}

the oil content per cell was significantly higher than their distant parent, the low oil accumulator CC124 (Figure 7C). However, in the three mutants that are in the $c w 15$ background, the oil content was clearly not higher than in $c w 15$ or in their direct progenitor 330 . When oil content was measured 4 days after $\mathrm{N}$ depletion, there was still no difference between the starchless mutants and their progenitor 330 (data not shown). This clearly showed that in the $c w 15$ background blocking starch synthesis did not result in over-accumulation of oil compared to the progenitor strain. TAG content was further analyzed in 9 independent complemented lines of the cw15sta6 mutant. Eight of these lines showed almost complete complementation for starch content ( $>30 \mu \mathrm{g}$ per million cell compared to about 50 $\mu \mathrm{g}$ in the wild-type progenitor 330). Almost all these eight lines had an oil content per cell not significantly lower than that of the cw15 sta6 mutant (Figure 8). This confirmed that the sta 6 mutation did not cause TAG over-accumulation. Moreover, when all the wild-type mutant and complemented strains tested were compared, no significant correlation between oil and starch content was found (Figure 8). Most importantly, the C8 line partially complemented for starch $(10 \mu \mathrm{g}$ per million cell vs. $50 \mu \mathrm{g}$ in 330) did not show higher oil than $c w 15$ or 330 . Taken together these results argued strongly against a competition between oil and starch synthesis in the $c w 15$ background.
It should be noted that in these experiments arginine was added to the preculture medium of the control strain 330 (this strain is auxotroph for arginine). However, arginine was omitted from the $\mathrm{N}$-depleted medium. Indeed, arginine is a source of nitrogen for C. reinhardtii $[26,27]$ and would create a bias in the comparison of 330 to the starchless mutants. As shown on Figure 7B, the addition of arginine in TAP-N cultures at the concentration normally used for precultures $\left(100 \mu \mathrm{g} \mathrm{mL}^{-1}\right)$ reduced the content of oil in 330 by half compared to the TAP-N medium without arginine added. This reduction in oil content in response to arginine addition was also observed in $c w 15$ strain (data not shown).

Oil and starch accumulated during $\mathrm{N}$ starvation phase are rapidly mobilized upon switching to nutrient replete conditions

To gain more insights into the dynamics of oil and starch reserves and find conditions that will be useful to screen for mutants impaired in oil degradation, experimental conditions causing TAG breakdown were sought and kinetics of mobilization were determined. C. reinhardtii cells were first starved for 3 days under TAP-N in the light to induce accumulation of reserves. Then, to create a need for carbon source and achieve conditions likely to involve reserve mobilization, cells were transferred to Tris-Minimal Media (MM) with nitrogen, and 


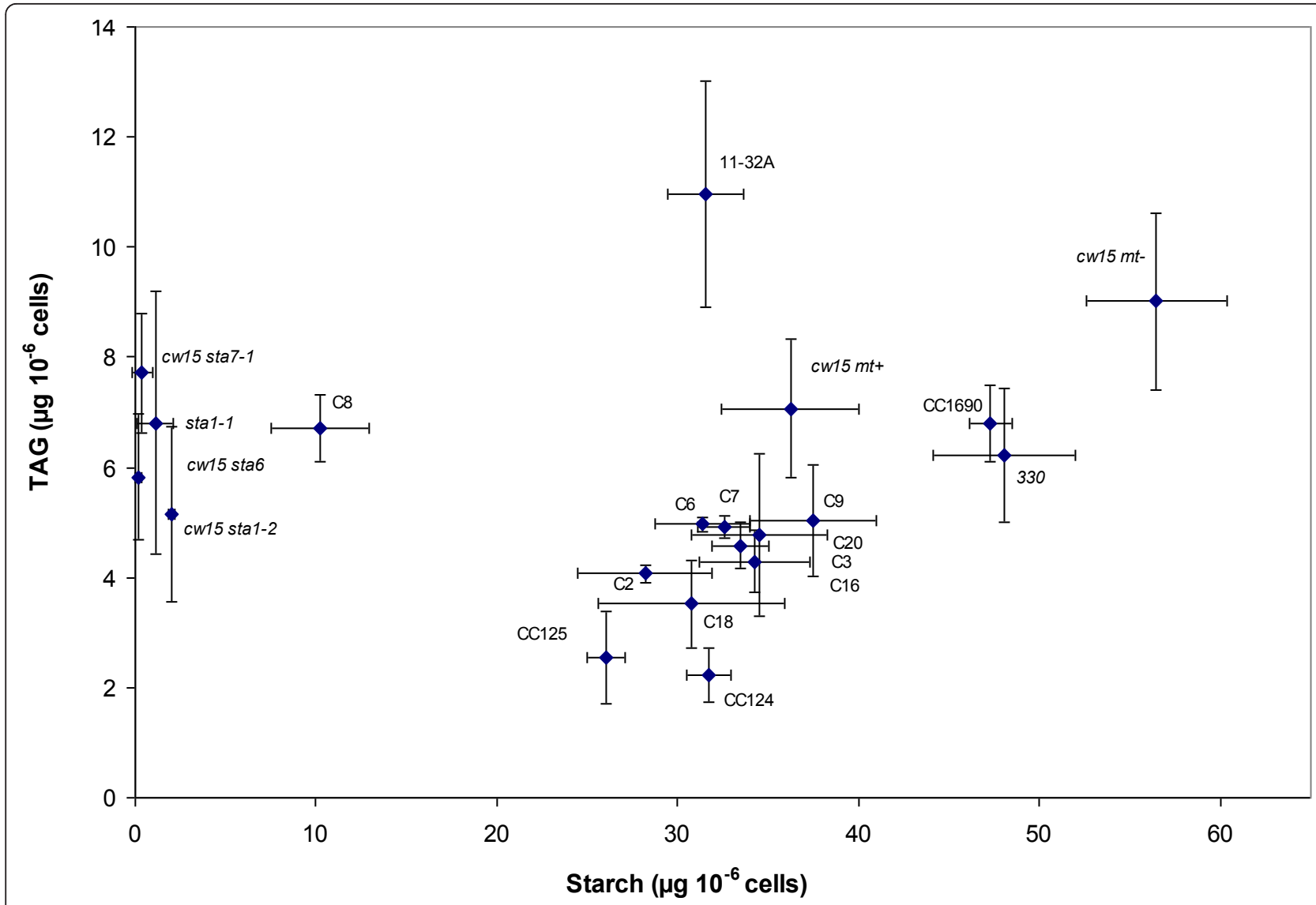

Figure 8 Absence of correlation between oil and starch content in various Chlamydomonas reinhardtii strains. C2,3,6,7,8,9,16,18,20 are independent lines of complementants for sta6 (BafJ5). Mean contents in starch and oil were calculated based on at least three independent experiments. Error bars indicate standard deviations. Mean content in oil and starch were subjected to a Kendall rank correlation test. The null hypothesis that oil and starch are independent cannot be rejected (tau statistics $=0.07$; two-tailed $p=0.673 ; n=20$ ).

kept in the dark for 3 days. Cellular oil and starch content was followed during this dark period. Starch degradation was found to occur very rapidly after switching to dark and started earlier than oil degradation (Figure 9). After 20 hours, $70 \%$ starch had already been catabolised to support growth while oil breakdown only begun. The bulk of oil was degraded between 20 and 24 hours of $\mathrm{N}$ resupply. Starch degradation continued between 20 and 60 hours while TAGs remained constant at $\sim 1 \mu \mathrm{g} 10^{-6}$ cells, a level equivalent to that of healthy grown un-starved cells. After 24 hours cells became green again (data not shown). The apparent decrease in starch and oil content per cell was not due to dilution by cell division because expression on a per $\mathrm{mL}$ culture resulted in similar results (additional file 3 ). It thus appears that $C$. reinhardtii can use both oil and starch but that there is a differential mobilization of these two types of reserves. The observation that starch is accumulated as well as degraded at a faster rate than the accumulation/degradation of TAGs is consistent with the view that in Chlamydomonas starch and oil have different purposes, starch being the reserve preferentially synthesized and mobilized and oil representing a long term storage in case of prolonged shortage or stress.

\section{Salt stress can induce oil accumulation in C. reinhardtii CC124}

So far, the most widely used stress to trigger oil accumulation in microalgae is the removal of nitrogen from the culture medium. Other stress conditions such as high $\mathrm{pH}$, salinity, light or extreme temperatures have also been described as triggering TAG accumulation, but quantitative data are still lacking for C. reinhardtii [3].

High salt (at $1 \mathrm{M}$ ) has been reported to increase intracellular accumulation of TAGs by about $65 \%$ in cells of the marine microalga Dunaliella salina [28]. In order to test the effect of salt stress on the accumulation of storage compounds in $C$. reinhardtii, TAP culture media containing nitrogen were supplemented for 2 days with $0,20,50$, and $100 \mathrm{mM} \mathrm{NaCl}$. Cell wall-less strain $c w 15$ was not a strain of choice for this experiment because 


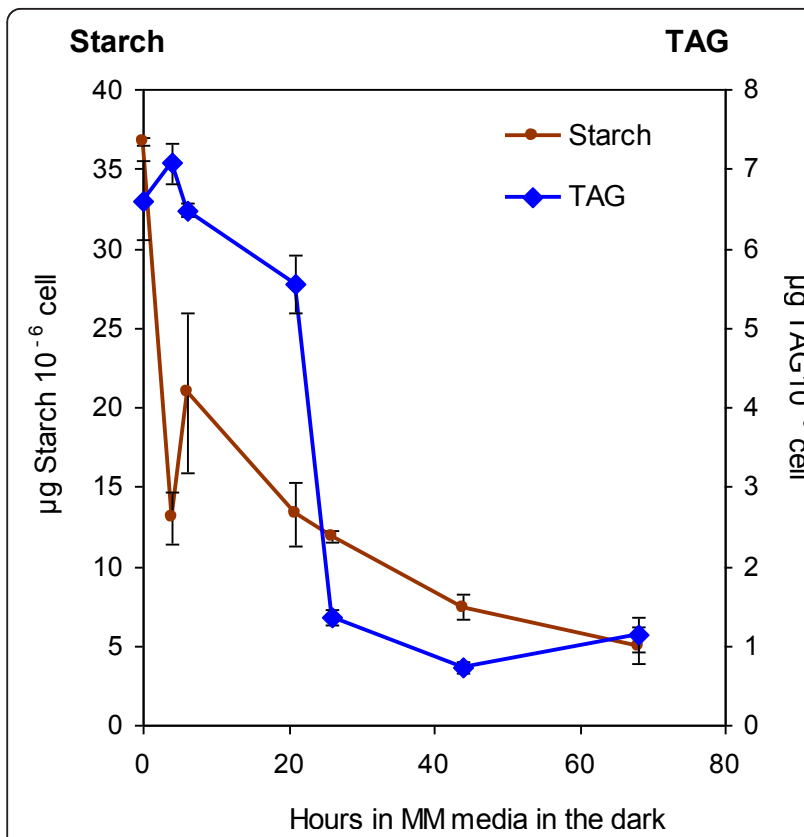

Figure 9 Mobilization of triacylglycerols and starch in strain 330 after re-supply with nitrogen. Cells were first cultivated in TAP medium until mid log phase, then transferred to TAP-N for 3 days under constant light and then switched to MM media in the dark. Values are mean of three independent experiments \pm SD

the absence of cell wall makes it more sensitive to high osmotic pressure. Thus, wild-type CC124 was used. We observed that both starch and TAG reserves increase with $\mathrm{NaCl}$ concentrations in TAP cultures (Figure 10). At $100 \mathrm{mM} \mathrm{NaCl}$, starch content was reached around $70 \mu \mathrm{g}$ per million cell, which was 4-fold higher than in TAP-N medium. TAGs went up to about $5 \mu \mathrm{g}$ per million cell, a level similar to that reached by this strain under $\mathrm{N}$ deprivation. Under these salt stress conditions, growth was stopped as observed for $\mathrm{N}$ deprivation.

\section{Discussion}

How to trigger oil synthesis and increase oil content in vegetative cells (plant leaves or microalgae) is a hot topic in many industrial and academic labs across the globe. In this study, we characterize oil accumulation in the model green microalgae Chlamydomonas reinhardtii and show that the level of oil accumulation caused by nitrogen deficiency in common laboratory strains is highly dependent on the strain used. The comparison of the oil content in various starchless mutants and their direct progenitors in two different genetic backgrounds reveals that carbon allocation between starch and oil pathways in $\mathrm{N}$-starved Chlamydomonas cells is likely to be more complex than previously thought. Substitution of $\mathrm{N}$ depletion by salt stress highlights the importance of culture conditions and stress perception in building oil reserves.

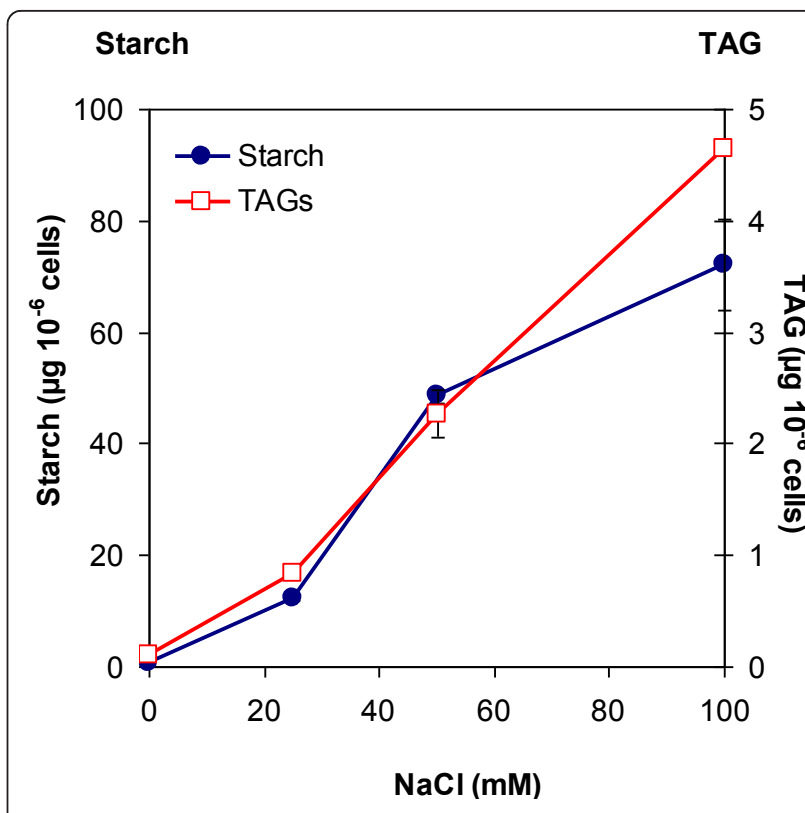

Figure 10 Effect of salt supplementation on starch and triacylglycerol content in C. reinhardtii. Wild-type strain CC124 was used. Cells were first cultivated in standard TAP medium reaching mid-log phase. Different $\mathrm{NaCl}$ amounts were then added to the cultures, which were further grown for 2 days before samples were taken for starch and lipid analyses. Values are mean of three independent experiments \pm SD.

\section{Factors critical for assessing effect of mutations on oil} content

Several reports on Chlamydomonas mutants affected in oil content have been recently published. Li et al $[17,22]$ showed that on a dry weight basis the oil content in the starchless and cell wall-less mutant cw15sta6 (BafJ5) is 10-fold higher than the wild-type strain CC1690 containing a cell wall. Work et al [19] observed that cw15sta 6 makes 2-fold more oil on a cell basis compared to the cell wall-containing and low oil accumulator CC124 (137C) strain. Wang et al [18] reported that after 18 hour of $\mathrm{N}$-depletion, cw15sta6 make 1.5-2.0 times more oil on a cell basis than an arginine revertant or a suppressed clone of 330. Data on starchless mutants presented here highlight that two factors are critical when comparing oil contents: $i$ ) the strain used as a control (i.e. direct progenitor or other strain) and ii) the basis on which data are expressed (i.e. per cell or per dry weight). Conclusion drawn from oil content comparisons can be different and even opposite depending on the reference basis and control strain used. This is illustrated on Figure 11. Concerning the control strain, it is clear that if one uses a reference strain with cell wall such as CC124 (137C) (Figure 11A), the conclusion drawn will be that sta 6 mutation is responsible for increased oil content in cw15sta 6 as recently suggested $[17,19]$. However, comparison using the direct 


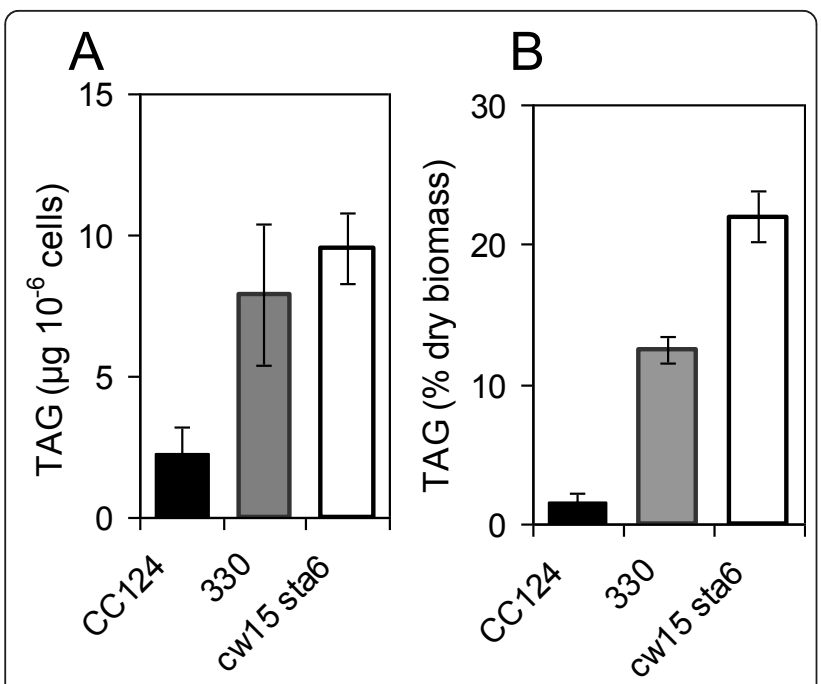

Figure 11 Influence of reference basis and control strains when comparing oil content. TAG amount is expressed on a $\mu \mathrm{g}$ $10^{-6}$ cells basis (A) or a $\%$ dry weight basis (B). Two reference strains, CC124 (137C) and the cell wall-less 330 (CW15arg7-7) are shown. Cells were cultured in TAP-N for 2 days. Values are mean of four independent experiments \pm SD.

progenitor 330 ( $\mathrm{cw} 15 \mathrm{arg} 7-7$ ) shows that there is no significant effect of the sta 6 mutation on oil accumulation (Figure 11A).

The importance of reference basis is also illustrated on Figure 11: the mutant strain $c w 15$ sta 6 makes about twice more oil than 330 on a dry weight basis (Figure 11B) but on a cell basis it makes similar amount of oil (Figure 11A). This is actually not surprising because starch makes significant contribution to cell dry weight (over $50 \%$ dry weight in 330 ). Although informative from the point of view of the enrichment of the biomass in oil, the dry weight basis can be misleading when assessing the effect of engineering strategies on the metabolism of a cell. Indeed, mutant strains might show large differences in dry weight per cell compared to wild-type. The per cell basis is thus more appropriate for metabolic engineering comparisons because it reflects the actual capacity of the oil biosynthesis pathway in cells, independently of other products such as cell wall and starch which might contribute very substantially to dry weight.

\section{Interaction between starch and oil depositions}

Starch and oil are two major carbon sinks in growth arrested cells [29]. The idea of a competition between starch and oil syntheses is clearly not supported by the fact that in the cell wall-less background $c w 15$ no increase in oil was observed in three starchless mutants compared to their direct progenitor or to complementants. In the cell wall containing CC124 (137C) background, the starchless mutant sta1-1 has about 3fold more oil than its progenitor CC124 (Figure 7C). It should be noted however that there is no evidence that the increase in oil is caused by the sta1-1 mutation. Sta 1-1 has been obtained by X-ray mutagenesis and might carry many additional mutations affecting oil content. The high variability in oil observed in wild-type strains suggests that mutations affecting oil content are common. Unfortunately, genetic analysis cannot be performed to prove that sta1-1 mutation is responsible for increased oil because sta1-1 mutant cannot be crossed. In summary, although it cannot be completely ruled out that the effect of blocking starch synthesis is dependent on the genetic background, current evidence on mutants and complementants in $c w 15$ background shows that blocking starch synthesis does not result in over-accumulation of oil in Chlamydomonas cells. Therefore, allocation of $\mathrm{C}$ precursors to reserves in $\mathrm{N}$-starved C. reinhardtii seems to involve more subtle relationships than a mere competition between oil and starch syntheses. This view is also clearly supported by the fact that the high oil accumulator 11-32A has normal level of starch (Figure 3). Another evidence of complexity of carbon partitioning comes from the observation that complemented mutant lines of cw15sta7-10 not only restored their wild-type starch levels, but also make more oil than the mutant [19].

The idea that impairement of starch synthesis in photosynthetic organisms does not necessarily result in higher oil content is also illustrated by data in higher plants. In Pisum sativum, a starchless mutant (rug3) defective in the plastid phosphoglucomutase gene which has almost lost all its starch reserve, was found to have a significantly increased seed lipid content [30], whereas mutation in the Arabidopsis ortholog (pgm-1) leads to a $40 \%$ reduction in oil content compared to wild-type seeds [31]. A transient starch accumulation has been postulated to provide a carbon source for lipid synthesis during accumulation phase in plant photosynthetic tissues [32]. This hypothesis is yet to be tested in C. reinhardtii.

\section{Origin of the high variability in oil content in common laboratory strains of Chlamydomonas}

High variation in oil content in Chlamydomonas reference strains is clearly an issue that has been overlooked so far and, as discussed above, has important practical applications when comparing oil contents in mutants. Concerning the cause of this variation between laboratory strains (which all originate from the same 1945 isolate of G.M. Smith) [33], we can only speculate that among the mutations accumulating in the haploid cells of Chlamydomonas during growth and storage in laboratories, many factors affect oil indirectly (possibly 
because TAG synthesis is a response to stress and adverse conditions). C. reinhardtii is a soil dwelling alga [21]. As for other unicellular or pluricellular organisms, accumulation of TAGs might have important roles for cell survival in some Chlamydomonas strains in their natural environments. In their natural habitat, microalgae often accumulate oil and/or starch in adverse circumstances such as a nutrient shortage. When the conditions become favourable, stored carbon reserves are usually fuelled up to support cell division and vegetative growth. Other putative roles of TAGs in microalgae include energy storage for germination of zygote and flotation/swimming of vegetative cells to the surface of ponds or other habitats, and membrane turnover and detoxification of endogenous or exogenous free fatty acids. Low selective pressure on high TAG content that is applied in strains cultivated under standard growth conditions in the laboratory might have resulted in accumulation of mutations lowering oil content.

Whether the high TAG accumulation observed in the cell-wall deficient strains $c w 15$ and 330 is actually caused by the absence of cell wall is unclear. Possible mechanisms linking cell wall and oil synthesis include increased sensitivity to stress caused by cell wall deficiency, changes in osmolarity or cell turgor, or changes in the nutrient $(\mathrm{N})$ perception and sensing machinery or enzymes located inside the cell wall or in the periplasm [34]. Nonetheless the disturbance in cell wall synthesis triggering oil accumulation is not new and has been previously observed in many diatoms, for example, the deficiency of silica, a major component of diatom cell walls, leads to much more pronounced oil accumulation than any other nutrient deficiency (including nitrogen or phosphate) [35]. Further work on other cell wall-less mutants is clearly needed to prove or disprove a causal relationship between cell wall integrity and oil accumulation.

\section{Chlamydomonas as a model to study lipid metabolism}

Chlamydomonas was originally classified as a microalga not suitable to study oil accumulation based on the low oil content of the strain investigated [36]. Our data show that strains of Chlamydomonas such as $c w 15$ and 11-32A accumulate high amounts of oil and are thus good models for further studies aiming at isolating low oil mutants. Even 137C (CC124) could be used for this purpose because the low amounts of TAGs produced by this strain can be measured by the HPTLC we used.

Concerning the isolation of Chlamydomonas lipid mutants, the effect of salt addition provides a convenient alternative to $\mathrm{N}$-depletion procedures for inducing oil accumulation in mutant screens, which are often performed in microplates. Removal of $\mathrm{N}$ by progressive depletion cannot be controlled in microplates, and centrifugations to change the medium are difficult or impossible to achieve depending on the strain with or without flagella. The rapid decrease in stored TAGs we have evidenced under certain conditions (Figure 9) could also serve as a basis for a screen aiming at isolating mutants affected in oil degradation. Isolating such mutants is important because continuous TAG degradation could occur and limit oil build up in Chlamydomonas as was shown in plant leaves [37].

Polyunsaturated fatty acids are easily oxidized and thus not desirable for biodiesel. The low content in these fatty acid species in Chlamydomonas shows some microalgal oil could be used for biodiesel without much additional genetic modifications. Further genetic engineering strategies aiming at fatty acyl chain modification could be directed toward expressing short or medium chain fatty acyl-ACP thioesterases to produce other fatty acids such as C10:0-C14:0.

\section{Conclusions}

Crops used today have been selected throughout ages for increased abilities to store reserve compounds such as oil or starch as well as for increased adaptation to agricultural practices [38]. Mass cultivation of microalgae is still in its infancy and will certainly need a domestication of species to improve lipid productivity, but also to adapt strain characteristics to technologies used for mass cultivation. Our data suggest that oil mutants should be assessed very cautiously and that approaches aiming at modifying growth and stress conditions in different genetic backgrounds might constitute interesting alternatives to metabolic engineering strategies in view of increasing oil yields.

\section{Methods}

\section{Strains and cultivation conditions}

Chlamydomonas reinhardtii wild-type, low starch and starchless mutant strains and their genotypes used in this study are described in Table 1. Briefly, sta1-2 (Baf)3), sta6 (BafJ5), and sta7-1 (Bafj6) strains were generated from cell wall deficient arginine-requiring strain 330 ( $m t+$ nit1 nit2 cw15 arg7-7) by random integration of cassette pARG7 in the nuclear genome [24,25,39]. Mutant strain sta1-1 (I7) is derived by X-ray mutagenesis of wild-type strain CC124 (137C) [13]. Unless stated otherwise, strain $c w 15$ used in this study is the mating type $m t$-. Complemented lines of sta6 (BafJ5) mutant (BafJ5C2, 3, 6, 7, 8, 9, 16, 18, 20) were generated by complementation with plasmid pSL18-STA6 and transformants selected based on paromomycine resistance. These lines were kindly provided by the Steven Ball lab (University of Lille, France).

Unless stated otherwise, all strains were grown at $24^{\circ} \mathrm{C}$ in continuous light $\left(150 \mu\right.$ moles photons $\left.\mathrm{m}^{-2} \mathrm{~s}^{-1}\right)$ in the 
presence of acetate in liquid cultures under shaking (120 $\mathrm{rpm}$ ). Standard Tris-Acetate-Phosphate (TAP) medium, which includes $7.5 \mathrm{mM} \mathrm{NH}_{4} \mathrm{Cl}$, is detailed in [33]. For nitrogen starvation studies, exponential phase $\left(5 \times 10^{6}\right.$ cells $\mathrm{mL}^{-1}$ ) cultures were centrifuged at $600 \mathrm{~g}$ for $5 \mathrm{~min}$ at room temperature, cell pellets kept and washed twice in TAP medium without nitrogen (TAP-N). Pellets were then resuspended in TAP-N medium and cells grown under constant light under shaking. For the cell walldeficient arginine-requiring strain 330, arginine $100 \mu \mathrm{g}$ $\mathrm{mL}^{-1}$ was added to the TAP medium but was omitted from TAP-N. To prepare the Tris-Minimal Medium (MM), solution was titrated to $\mathrm{pH} 7.0$ with $\mathrm{HCl}$ instead of acetic acid. Cell growth and cell size were monitored by cell counts with automated cell counter (Multisizer ${ }^{\mathrm{TM}}$ 3 Coulter Counter, Beckman Coulter, USA).

\section{Fluorescent microscopy}

Nile red is a general fluorescent lipophilic stain [20] widely used to reveal the presence of lipid droplets in various microorganisms or plant parts [40]. C. reinhardtii cells were stained by a 20 min incubation in the dark at room temperature in a $0.1 \mu \mathrm{g} \mathrm{mL}^{-1}$ solution of Nile red (Sigma, Saint Louis, USA). Nile red stock solution was $0.1 \mathrm{mg} \mathrm{mL}^{-1}$ in methanol. In the presence of neutral lipids, Nile red emits a yellow-gold fluorescence $\left(\lambda_{\max }=\right.$ $580 \mathrm{~nm}$ ) while in the presence of polar lipids Nile red emits an orange-red fluorescence $\left(\lambda_{\max }=615 \mathrm{~nm}\right)$ [20]. Nile red fluorescence was observed with a Leica DMRXA epifluorescent microscope equipped with a $63 x / 1.6$ oil immersion objective (Leica Microsystems, Germany), using ByPass excitation (475/40) and LongPass barrier (510) filters. Images were captured with the Spot Insight 4 software (Diagnostic Instruments Inc., Sterling Heights, USA).

\section{Transmission electron microscopy}

C. reinhardtii cells grown in the presence of $\mathrm{N}$ were harvested by centrifugation $(600 \mathrm{~g}, 10 \mathrm{~min})$ at mid-log phase and, after three days of $\mathrm{N}$ starvation, fixed with $2.5 \%$ glutaraldehyde in $0.2 \mathrm{M}$ cacodylate buffer ( $\mathrm{pH} 7.4$ ) for 2 days at $4{ }^{\circ} \mathrm{C}$ and rinsed three times 5 min with 0.2 $\mathrm{M}$ cacodylate buffer. Cells were then post-fixed for $1 \mathrm{~h}$ at $4^{\circ} \mathrm{C}$ using $1 \%$ osmium tetroxide in $0.2 \mathrm{M}$ cacodylate buffer ( $\mathrm{pH}$ 7.4), dehydrated in increasing concentrations of ethanol (5 min 70\% ethanol, $10 \mathrm{~min} 95 \%$ ethanol and 10 min 100\% ethanol) and embedded in EMBED 812. Ultrathin sections of either 70 or $90 \mathrm{~nm}$ were stained with uranyl acetate followed by lead citrate and examined with a Zeiss electron microscope EM912 (Carl Zeiss, Jena, Germany). Digital images were acquired with a Gatan Bioscan CCD camera (Gatan GmbH, München, Germany).

\section{Starch and chlorophyll quantification}

Starch measurements were performed using an experimental protocol adapted from [41]. C. reinhardtii cells (about $\left.2 \times 10^{6}\right)$ were harvested by centrifugation $(13,000$ $g$, $10 \mathrm{~min})$. Cell pellets were resuspended in $1 \mathrm{~mL}$ methanol for chlorophyll extraction, mixed vigorously for $1 \mathrm{~min}$ and centrifuged. Supernatants were used to quantify chlorophyll photometrically [42], and pellets were left to dry in the hood to remove residual methanol. Pellets were then resuspended in $400 \mu \mathrm{L}$ of distilled $\mathrm{H}_{2} \mathrm{O}$, and autoclaved for $15 \mathrm{~min}$ at $120^{\circ} \mathrm{C}$ for starch solubilization. Total starch was quantified using an enzymatic starch assay kit including a commercial amyloglucosidase solution to convert starch to glucose (Sigma-Aldrich ref. SA-20, Saint Louis, USA). Glucose was quantified using an automated YSI 2700 select sugar analyzer (YSI Life Sciences, Yellow Springs, USA) using glucose as standard.

\section{Lipid analyses}

Several methods of oil quantification are available in the literature including gravimetric measurement, glycerol analysis, NMR, or GC-FID. The most common is total lipid extraction with a Bligh and Dyer procedure [43], followed by separation on a Thin Layer Chromatography (TLC), recovery of the triacylglycerol (TAG) from the silica, transmethylation and quantification of the fatty acid methyl esters (FAMEs) by Gas Chromatography with Flame Ionization Detector (GC-FID). A drawback of this method is that it is tedious and time consuming. A simplified protocol using direct transmethylation of tissues [44] which is routinely used for biological material such as oilseeds (where TAGs represent the vast majority of lipids), might be applied to microalgal cultures but for screening purposes only. It is not suitable for precise quantification of TAGs in cells such as C. reinhardtii where oil might represent only a fraction of total cellular lipid content. A method for neutral lipid estimation in $C$. reinhardtii based on Nile red is available [45] but is mainly qualitative. The procedure we used is based on total lipid extraction, TLC and densitometry. It allows specific quantification of TAGs and can be used in medium throughput screenings.

\section{Extraction of total cellular lipids}

Lipids were extracted from C. reinhardtii cells by modified Bligh and Dyer [43]. Briefly, cells (usually 5 million) were harvested by centrifugation at $10,000 \mathrm{~g}$ for $10 \mathrm{~min}$ and $1 \mathrm{~mL}$ of $1 \mathrm{mM}$ EDTA in $0.15 \mathrm{M}$ acetic acid was added. The mixture was transferred to a glass tube with Teflon-lined screw cap and, after addition of $3 \mathrm{ml}$ methanol:chloroform $(2: 1, \mathrm{v} / \mathrm{v})$, was vortexed for $10 \mathrm{~min}$ with a multi-tube vortexer (VX-2500, VWR). Then, 1 $\mathrm{mL}$ of chloroform and $0.8 \mathrm{ml}$ of $\mathrm{KCl} 0.88 \%(\mathrm{w} / \mathrm{v})$ were 
added before vortexing and centrifuging at $4000 \mathrm{rpm}$ for $2 \mathrm{~min}$. The lower chloroform phase was transferred to a new glass tube. Cells were then extracted again with hexane, centrifuged and the supernatant was combined with the previous chloroform extracts. Lipid extracts were dried under a stream of $\mathrm{N}_{2}$ and re-suspended in solvent for HPTLC or GC-FID analysis.

Quantification of oil content by high performance-thin layer chromatography (HPTLC)

Triacylglycerols (TAGs) were quantified using a densitometry method by comparing to a standard curve generated from known amounts of triheptadecanoin (C17:0 TAG) standard. Typically, around $0.5 \mu \mathrm{g}$ of lipid extract was loaded as a spot onto $20 \times 20 \mathrm{~cm}$ silica gel 60 F254 HPTLC plates (Merck KGaA, Germany) using an ATS 5 automatic TLC sampler (Camag, Switzerland). Plates were then developed fully once in an ADC2 automatic developing chamber (Camag) using a hexane/diethyl ether/acetic acid $(17 / 3 / 0.2, \mathrm{v} / \mathrm{v} / \mathrm{v})$ solvent mixture, thoroughly dried under the hood, dipped for $6 \mathrm{~s}$ in a modified $\mathrm{CuSO}_{4}$ reagent [46] (20 $\mathrm{g} \mathrm{CuSO}_{4}, 200 \mathrm{ml}$ methanol, $8 \mathrm{ml} \mathrm{H}_{2} \mathrm{SO}_{4}, 8 \mathrm{ml} \mathrm{H}_{3} \mathrm{PO}_{4}$ ), heated at $141^{\circ} \mathrm{C}$ for $30 \mathrm{~min}$ on a TLC plate heater and finally scanned using a TLC Scanner 3 with WinCATs software (Camag). Results obtained by this densitometry procedure were not significantly different from those obtained by recovery of the TAG fraction from the TLC plate, transmethylation and quantification of fatty acid methyl esters by gas chromatography with flame ionization detector (see below). All polar lipids such as galactolipids were also quantified by HPTLC/densitometry. Plates were developed with an acetone/toluene/water (91/30/8, v/v/v) solvent mixture. Lipid extracts were run alongside purified polar lipid standards (Sigma-Aldrich, Saint-Louis, USA; Larodan Fine Chemicals AB, Malmö, Sweden).

Preparation of fatty acid methyl esters (FAMEs),

identification by gas chromatography coupled to mass spectrometry (GC-MS) and quantification by gas chromatography with flame ionization detector (GC-FID)

FAMEs were prepared from Chlamydomonas total lipid extract in a glass tube with a Teflon-lined screw cap using acid-catalyzed transmethylation as described in $\mathrm{Li}$ et al. [44]. Internal standard used was triheptadecanoin (C17:0 TAG). FAMEs separation and identification was carried out on a FOCUS gas chromatograph equipped with DSQ II quadrupole mass spectrometer using the electron impact ionization mode (Thermo Fisher Scientific, San Jose, USA). A polar TR-WAX column ensuring good separation of polyunsaturated fatty acid species was used (Thermo Fisher Scientific; length 30 m, diameter $0.25 \mathrm{~mm}$, film thickness $0.25 \mu \mathrm{m}$ ). Hydrogen was the carrier gas. The injector and transfer line were maintained at $225^{\circ} \mathrm{C}$ and $250^{\circ} \mathrm{C}$ respectively. The source temperature was $200^{\circ} \mathrm{C}$. Samples were injected in split mode (5:1 split ratio) at an oven temperature of $45^{\circ} \mathrm{C}$. After $1.5 \mathrm{~min}$, the oven temperature was raised to $150^{\circ} \mathrm{C}$ at $15^{\circ} \mathrm{C} \mathrm{min}{ }^{-1}$ then

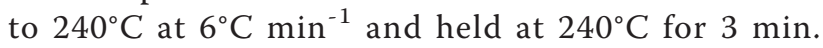
FAMEs were identified by retention time, fragmentation pattern and, when necessary, comparison with purified FAME standards (Larodan Fine Chemicals AB, Malmö, Sweden). FAMEs were quantified with a GC-FID (Thermo Fisher Scientific, San Jose, USA). Samples were injected in split mode (split ratio 1:5). Detector was set at $250^{\circ} \mathrm{C}$. Carrier gas, column and oven temperature program were the same as for GC-MS analysis. For the TAG fraction, the fatty acid composition was determined as follows. TAGs were separated from other lipids by HPTLC as described above and the TAG fraction was revealed by spraying with primuline $(0.005 \%$ in $80 \%$ acetone) and visualized under UV light. The silica corresponding to the TAG fraction was carefully scrapped off the TLC plate and packed into a Pasteur pipette plugged with a bit of glass wool. TAGs were eluted with a chloroform/methanol $/ \mathrm{H}_{2} \mathrm{O}(5 / 5 / 1, \mathrm{v} / \mathrm{v} / \mathrm{v})$ mixture and a final rinse with hexane. The TAG extract was recovered, dried under a stream of $\mathrm{N}_{2}$ and FAMEs were prepared and analyzed by GC-MS or GC-FID.

\section{Additional material}

Additional file 1: Kinetics of oil accumulation in Chlamydomonas reinhardtii strain CC124 and $\mathrm{cw} 15$ (mean $\pm \mathrm{SD}, \mathrm{n}=3$ )

Additional file 2: Changes in fatty acid composition in $C$. reinhardtii during $\mathrm{N}$ depletion (mean $\pm S D, n=3$ ).

Additional file 3: Mobilization of triacylglycerols and starch in strain 330 after re-supply with nitrogen expressed on a per $\mathrm{mL}$ culture basis. Cells were first cultivated in TAP medium until mid log phase, then transferred to TAP-N for 3 days under constant light and then switched to MM media in the dark. Values are mean of three independent experiments \pm SD.

\section{Acknowledgements}

We thank Prof. Steven Ball and Dr. David Dauvillée (University of Lille, France) for generous gift of the starchless mutants and their complementants. The work is supported by financial support from the French ANR [SHAMASH (ANR-06-BIOE-013) and ALGOMICS (ANR-08-BIOE002)] and by the CNRS program LIP-ALG. Support was also provided by the HélioBiotec platform, funded by the European Union (FEDER), the Région Provence Alpes Côte d'Azur, the French Ministry of Research, and the CEA.

\section{Author details}

${ }^{1}$ Commissariat à l'Energie Atomique et aux Energies Alternatives (CEA), Direction of Life Sciences, Institute for Environmental Biology and Biotechnology, Laboratory of Bioenergetics and Biotechnology of Bacteria and Microalgae, CEA Cadarache, 13108 Saint-Paul-lez-Durance, France. ${ }^{2}$ Centre National de la Recherche Scientifique (CNRS), UMR 6191, CEA Cadarache, 13108 Saint-Paul-lez-Durance, France. ${ }^{3}$ Aix Marseille Université, Department of Plant Biology and Environmental Microbiology, CEA Cadarache, 13108 Saint-Paul-lez-Durance, France. ${ }^{4}$ Current Address: Fermentalg SA, 33500 Libourne, France. 


\section{Authors' contributions}

$M S, F B, C T, Y L B, G P$ designed the experiments. MS, SC, YLB, MN, BF, CC, AB, $P C$ performed the experiments. YLB, FB, GP wrote the manuscript. All authors read and approved the manuscript.

Received: 11 October 2010 Accepted: 21 January 2011

Published: 21 January 2011

\section{References}

1. Schubert C: Can biofuels finally take center stage? Nat Biotech 2006 , 24(7):777-784

2. Chisti Y: Biodiesel from microalgae. Biotechnol Adv 2007, 25(3):294-306.

3. Hu Q, Sommerfeld M, Jarvis E, Ghirardi M, Posewitz M, Seibert M, Darzins A: Microalgal triacylglycerols as feedstocks for biofuel production: perspectives and advances. Plant J 2008, 54(4):621-639.

4. Rodolfi L, Zittelli GC, Bassi N, Padovani G, Biondi N, Bonini G, Tredici MR: Microalgae for oil: Strain selection, induction of lipid synthesis and outdoor mass cultivation in a low-cost photobioreactor. Biotechnol Bioeng 2009, 102(1):100-112.

5. Hicks GR, Hironaka CM, Dauvillee D, Funke RP, D'Hulst C, Waffenschmidt S, Ball SG: When simpler is better. Unicellular green algae for discovering new genes and functions in carbohydrate metabolism. Plant Physiol 2001, 127(4):1334-1338.

6. Han Y, Parsons CM, Alexander DE: Nutritive-value of high oil corn for poultry. Poultry Sci 1987, 66(1):103-111.

7. Tornabene TG, Holzer G, Lien S, Burris N: Lipid-composition of the nitrogen starved green-alga Neochloris oleoabundans. Enzyme Microb Tech 1983, 5(6):435-440.

8. Rochaix JD: Chlamydomonas, a model system for studying the assembly and dynamics of photosynthetic complexes. FEBS Letters 2002, 529(1):34-38.

9. Ball SG, Dirick L, Decq A, Martiat JC, Matagne RF: Physiology of starch storage in the monocellular alga Chlamydomonas reinhardtii. Plant Sci 1990, 66(1):1-9.

10. Marshall WF: Chapter 1 Basal bodies: platforms for building cilia. In Current Topics in Developmental Biology. Volume 85. Edited by: Bradley KY. Academic Press; 2008:1-22.

11. Merchant SS, Prochnik SE, Vallon O, Harris EH, Karpowicz SJ, Witman GB, Terry A, Salamov A, Fritz-Laylin LK, Maréchal-Drouard L, Marshall WF, Qu LH, Nelson DR, Sanderfoot AA, Spalding MH, Kapitonov W, Ren $Q$, Ferris P, Lindquist E, Shapiro H, Lucas SM, Grimwood J, Schmutz J, Cardol P, Cerutti H, Chanfreau G, Chen CL, Cognat V, Croft MT, Dent R, Dutcher S, Fernández E, Fukuzawa H, González-Ballester D, GonzálezHalphen D, Hallmann A, Hanikenne M, Hippler M, Inwood W, Jabbari K, Kalanon M, Kuras R, Lefebvre PA, Lemaire SD, Lobanov AV, Lohr M, Manuell A, Meier I, Mets L, Mittag M, Mittelmeier T, Moroney JV, Moseley J, Napoli C, Nedelcu AM, Niyogi K, Novoselov SV, Paulsen IT, Pazour G, Purton S, Ral JP, Riaño-Pachón DM, Riekhof W, Rymarquis $L$, Schroda M, Stern D, Umen J, Willows R, Wilson N, Zimmer SL, Allmer J, Balk J, Bisova K, Chen CJ, Elias M, Gendler K, Hauser C, Lamb MR, Ledford H, Long JC, Minagawa J, Page MD, Pan J, Pootakham W, Roje S, Rose A, Stahlberg E, Terauchi AM, Yang P, Ball S, Bowler C, Dieckmann CL, Gladyshev VN, Green P, Jorgensen R, Mayfield S, MuellerRoeber B, Rajamani S, Sayre RT, Brokstein P, Dubchak I, Goodstein D, Hornick L, Huang YW, Jhaveri J, Luo Y, Martínez D, Ngau WC, Otillar B, Poliakov A, Porter A, Szajkowski L, Werner G, Zhou K, Grigoriev IV, Rokhsar DS, Grossman AR: The Chlamydomonas genome reveals the evolution of key animal and plant functions. Science 2007, 318(5848):245-250.

12. Grossman AR, Croft M, Gladyshev VN, Merchant SS, Posewitz MC, Prochnik S, Spalding MH: Novel metabolism in Chlamydomonas through the lens of genomics. Curr Opin Plant Biol 2007, 10(2):190-198.

13. Ball S, Marianne T, Dirick L, Fresnoy M, Delrue B, Deca A: A Chlamydomonas reinhardtii low-starch mutant is defective for 3-phosphoglycerate activation and orthophosphate inhibition of ADP-glucose pyrophosphorylase. Planta 1991, 185(1):17-26.

14. Moellering ER, Benning C: RNA interference silencing of a major lipid droplet protein affects lipid droplet size in Chlamydomonas reinhardtii. Eukaryot Cell 2010, 9(1):97-106.
15. Riekhof WR, Sears BB, Benning C: Annotation of genes involved in glycerolipid biosynthesis in Chlamydomonas reinhardtii: Discovery of the betaine lipid synthase BTA1(Cr). Eukaryot Cell 2005, 4(2):242-252.

16. Ramazanov A, Ramazanov Z: Isolation and characterization of a starchless mutant of Chlorella pyrenoidosa STL-PI with a high growth rate, and high protein and polyunsaturated fatty acid content. Phycol Res 2006, 54(4):255-259.

17. Li Y, Han D, Hu G, Dauvillee D, Sommerfeld M, Ball S, Hu Q: Chlamydomonas starchless mutant defective in ADP-glucose pyrophosphorylase hyper-accumulates triacylglycerol. Metab Eng 2010, 12(4):387-391.

18. Wang ZT, Ullrich N, Joo S, Waffenschmidt S, Goodenough U: Algal lipid bodies: stress induction, purification, and biochemical characterization in wild-type and starchless Chlamydomonas reinhardtii. Eukaryot Cell 2009, 8(12):1856-1868

19. Work VH, Radakovits R, Jinkerson RE, Meuser JE, Elliott LG, Vinyard DJ, Laurens LML, Dismukes GC, Posewitz MC: Increased lipid accumulation in the Chlamydomonas reinhardtii sta7-10 starchless Isoamylase mutant and increased carbohydrate synthesis in complemented strains. Eukaryot Cell 2010, 9(8):1251-1261.

20. Greenspan P, Mayer EP, Fowler SD: Nile red - a selective fluorescent stain for intracellular lipid droplets. J Cell Biol 1985, 100(3):965-973.

21. Harris EH: Chlamydomonas as a model organism. Annu Review Plant Physiol Plant Mol Biol 2001, 52:363-406.

22. Li Y, Han D, Hu G, Sommerfeld M, Hu Q: Inhibition of starch synthesis results in overproduction of lipids in Chlamydomonas reinhardtii. Biotechnol Bioeng 2010, 107(2):258-68.

23. Mouille G, Maddelein ML, Libessart N, Talaga P, Decq A, Delrue B, Ball S: Preamylopectin processing: A mandatory step for starch biosynthesis in plants. Plant Cell 1996, 8(8):1353-1366.

24. Van den Koornhuyse N, Libessart N, Delrue B, Zabawinski C, Deca A, Iglesias A, Carton A, Preiss J, Ball S: Control of starch composition and structure through substrate supply in the monocellular alga Chlamydomonas reinhardtii. J Biol Chem 1996, 271(27):16281-16287.

25. Zabawinski C, Van den Koornhuyse N, D'Hulst C, Schlichting R, Giersch C, Delrue B, Lacroix JM, Preiss J, Ball S: Starchless mutants of Chlamydomonas reinhardtii lack the small subunit of a heterotetrameric ADP-glucose pyrophosphorylase. J Bacterio/ 2001, 183(3):1069-1077.

26. Kirk DL, Kirk MM: Carrier-mediated uptake of arginine and urea by Chlamydomonas reinhardtii. Plant Physiol 1978, 61(4):556-560.

27. Grossman A: Acclimation of Chlamydomonas reinhardtii to its nutrient environment. Protist 2000, 151(3):201-224.

28. Takagi M, Karseno Yoshida T: Effect of salt concentration on intracellular accumulation of lipids and triacylglyceride in marine microalgae Dunaliella cells. J Biosci Bioeng 2006, 101(3):223-226.

29. Klein U: Intracellular carbon partitioning in Chlamydomonas reinhardtii. Plant Physiol 1987, 85(4):892-897.

30. Casey R, Domoney C, Forster C, Hedley C, Hitchin E, Wang T: The effect of modifying carbohydrate metabolism on seed protein gene expression in peas. J Plant Physiol 1998, 152(6):636-640.

31. Periappuram C, Steinhauer L, Barton DL, Taylor DC, Chatson B, Zou JT: The plastidic phosphoglucomutase from Arabidopsis. A reversible enzyme reaction with an important role in metabolic control. Plant Physiol 2000, 122(4):1193-1199.

32. daSilva P, Eastmond PJ, Hill LM, Smith AM, Rawsthorne S: Starch metabolism in developing embryos of oilseed rape. Planta 1997, 203(4):480-487.

33. Harris EH: The genius Chlamydomonas. In The Chlamydomonas sourcebook: introduction to Chlamydomonas and its laboratory use. Volume 2009.. 2 edition. Elsevier;(1):1-18.

34. Vallon O, Bulte L, Kuras R, Olive J, Wollman FA: Extensive accumulation of an extracellular I-amino-acid oxidase during gametogenesis of Chlamydomonas reinhardtii. Eur J Biochem 1993, 215(2):351-360.

35. Roessler PG: Changes in the activities of various lipid and carbohydrate biosynthetic enzymes in the diatom Cyclotella cryptica in response to silicon deficiency. Arch Biochem Biophys 1988, 267(2):521-528.

36. Sheehan J, Dunahay T, Benemann J, Roessler PG: A look back at the US Department of Energy's aquatic species program - biodiesel from algae. Golden, CO: National Renewable Energy Laboratory: US Department of Energy's Office of Fuels Development; 1998. 
37. Slocombe SP, Cornah J, Pinfield-Wells H, Soady K, Zhang QY, Gilday A, Dyer JM, Graham IA: Oil accumulation in leaves directed by modification of fatty acid breakdown and lipid synthesis pathways. Plant Biotechnol J 2009, 7(7):694-703.

38. Purugganan $\mathrm{MD}$, Fuller $\mathrm{DQ}$ : The nature of selection during plant domestication. Nature 2009, 457(7231):843-848.

39. Dauvillée D, Colleoni C, Mouille G, Morell MK, d'Hulst C, Wattebled F, Liénard L, Delvallé D, Ral JP, Myers AM, Ball SG: Biochemical characterization of wild-type and mutant isoamylases of Chlamydomonas reinhardtii supports a function of the multimeric enzyme organization in amylopectin maturation. Plant Physiol 2001, 125(4):1723-1731.

40. Li-Beisson Y, Shorrosh B, Beisson F, Andersson M, Arondel V, Bates P, Baud S, Bird D, DeBono A, Durrett T, Franke R, Graham I, Katayama K, Kelly A, Larson T, Markham J, Miquel M, Molina I, Nishida I, Rowland O, Samuels L, Schmid K, Wada H, Welti R, Xu C, Zallot R, Ohlrogge J: Acyl lipid metabolism. In the Arabidopsis Book. Volume 8. Edited by: Last R. Rockville, MD: American Society of Plant Biologists; 2010:(1):1-65.

41. Klein U, Betz A: Fermentative metabolism of hydrogen-evolving Chlamydomonas moewusii. Plant Physiol 1978, 61(6):953-956.

42. Lichtenthaler HK: Chlorophylls and carotenoids - pigments of photosynthetic biomembranes. Method Enzymol 1987, 148:350-382.

43. Bligh EG, Dyer WJ: A rapid method of total lipid extraction and purification. Can J Biochem Physiol 1959, 37(8):911-917.

44. Li YH, Beisson F, Pollard M, Ohlrogge J: Oil content of Arabidopsis seeds: The influence of seed anatomy, light and plant-to-plant variation. Phytochemistry 2006, 67(9):904-915.

45. Chen W, Zhang CW, Song LR, Sommerfeld M, Hu Q: A high throughput Nile red method for quantitative measurement of neutral lipids in microalgae. J Microbiol Meth 2009, 77(1):41-47.

46. Churchward MA, Brandman DM, Rogasevskaia T, Coorssen JR: Copper (II) sulfate charring for high sensitivity on-plate fluorescent detection of lipids and sterols: quantitative analyses of the composition of functional secretory vesicles. J Chem Biol 2008, 1(1-4):79-87.

doi:10.1186/1472-6750-11-7

Cite this article as: Siaut et al:: Oil accumulation in the model green alga Chlamydomonas reinhardtii: characterization, variability between common laboratory strains and relationship with starch reserves. $B M C$ Biotechnology 2011 11:7.

\section{Submit your next manuscript to BioMed Central and take full advantage of:}

- Convenient online submission

- Thorough peer review

- No space constraints or color figure charges

- Immediate publication on acceptance

- Inclusion in PubMed, CAS, Scopus and Google Scholar

- Research which is freely available for redistribution

Submit your manuscript at www.biomedcentral.com/submit
C Biomed Central 